Roberto Tietzmann [PUC/RS]

\title{
Uma proposta de taxonomia de créditos de abertura cinematográficos
}

\author{
A proposal of a taxonomy for film opening credits
}

Créditos de abertura, taxonomia, comunicação gráfica

Os créditos de abertura de um filme representam um espaço híbrido onde elementos da comunicação gráfica e da linguagem cinematográfica se combinam através de diversas estratégias de retórica visual. Este estudo propõe uma taxonomia que agrupa estas estratégias em quatro quadrantes principais, com implicações estéticas e históricas.

Film credits, taxonomy, graphic design

Opening credits in a film represent a hybrid communication space where elements of graphic design and cinematographic language are combined through diverse strategies of visual rhetoric. This study proposes a taxonomy which groups these strategies in four main quadrants, with aesthetic and historical implications.

\section{Introdução}

Os pontos defendidos neste artigo são baseados em uma premissa simples: os créditos de abertura de um filme podem ser entendidos como uma espécie de linguagem híbrida entre 0 cinema e comunicação gráfica, recortada a partir das possibilidades mais amplas de ambas as linguagens e podendo ser estudada em seus elementos, recombinações, evolução histórica e soluções estético-visuais.

Tal hibridização permite a uma linguagem incorporar elementos da outra, surpreendendo o espectador pelo incomum e confortando-o ao reencontrar os paradigmas e sintagmas já conhecidos, sem constituir algo drasticamente diferente a ponto de necessitar de um aprendizado distinto para ler um filme, ler um material gráfico impresso e ler uma sequência de créditos. Os créditos continuam sendo, como definiu sinteticamente Ephraim Katz, uma lista de nomes dos envolvidos no filme que pode ganhar formas mais criativas (Katz, 1998:306). Tal perspectiva de mescla criativa está em sintonia com a condição da cultura contemporânea, como afirma Teixeira Coelho:

'Cada linguagem tem um tempo e um espaço próprios, o que significa que cada pós-modernidade é uma pós modernidade. Haverá uma zona comum, sem dúvida - mas feita muito mais de reverberações recíprocas entre as linguagens do que de correspondências feitas entre elas. (Teixeira Coelho, 1995:96)'

Uma linguagem pode ser entendida a partir de várias abordagens. A princípio a consideraremos como um sistema de significação, ou seja, um sistema que permite aos sujeitos envolvidos a troca de mensagens com produção de sentido na comunicação (Fiske, 1983). Obviamente, tanto o cinema (entendido aqui em um sentído múltiplo, representando tanto o aparato tecnológico quanto a indústria dele oriunda, o repertório de filmes, a linguagem específica dele oriunda, etc.) quanto a comunicação gráfica são ao mesmo tempo veículos de outras linguagens e áreas do conhecimento dotadas de um repertório específico de linguagem e significantes. Interessantes hibridizações acontecem quando o que é específico de uma área se sobrepõe à área vizinha.

\section{Especificidades e hibridizações}

O que é específico a primeira vista para o cinema (e os meios dele derivados) é o registro de imagem seqüencial que cria a ilusão de movimento por meios fotográficos, eletrônicos ou digitais acompanhado da captação de som que pode ser ou não utilizado posteriormente. Tais 


\section{Infodesıgn}

capacidades de registro foram amplamente divulgadas como o grande diferencial do novo meio, nascido em 1892 (segundo a tradição americana) ou 1895 (segundo a tradição francesa).

A célebre sessão parisiense de 28 de dezembro de 1895 no Salon Indien do Grand Café do Boulevard des Capucines (Barnouw, 1993:9) despertou um interesse imediato. Dezenas de aparelhos para filmar e projetar imagens em movimento foram lançados em diversos países da Europa ao final do século XIX, portando nomes tão surpreendentes como fototeágrafo, héliocinégrafo, fotobioscópio, cinetógrafo, fantógrafo, cinemágrafo, fototaquígrafo, movimentoscópio, badizógrafo, cronovivógrafo, clondiscoscópio e até mimimoscópio (MANNONI, 2003 ).

O uso mais imediato do cinematógrafo e seus semelhantes era caracterizado pelas suas capacidades miméticas de representação (Freitas , 2006:2), ou seja, permitia "que uma coisa que não estivesse presente em um determinado instante, ou seja, a realidade, pudesse se apresentar sob uma outra forma: em imagem". Os filmes lançados em 1895 e nos anos seguintes pelos Lumière seguiam este princípio e consistiam em registros do cotidiano francês, pequenos esquetes (como 'O Regador Regado', projetado na sessão inaugural) e vistas pelo mundo.

Eles não envolviam elenco, cenários artificiais, tramas sofisticadas, elementos gráficos ou efeitos visuais. Isto pode ser entendido não apenas como um uso limitado das possibilidades que o cinematógrafo permitia. Era uma busca pela separação conceitual do cinema, em um primeiro momento negando elementos identificáveis no teatro e afirmando as características mais imediatas do nascente meio. Esta mediação foi seu primeiro diferencial, definido tanto pela postura de Louis Lumière (Barnouw, 1993:9) quanto pela promessa afirmada e reafirmada de correspondência entre o que era visto na tela e o mundo real, externo à sala de espetáculo.

As capacidades técnico-miméticas dos aparelhos derivados do cinematógrafo, no entanto, não se restringiam ao registro de ações de pessoas em frente à câmera ou de vistas naturais. Como ocorrera antes com a fotografia, praticamente qualquer elemento que refletisse luz podia ser captado pelas lentes e impresso em filme, editado, duplicado e exibido. Tivesse tal assunto movimento inato ou não. Fosse de natureza gráfica ou cinematográfica.

A disputa entre a França e os Estados Unidos pelo domínio do mercado cinematográfico em pouco tempo se mostrou acirrada, marcada pela pirataria indiscriminada de filmes de parte a parte. Buscando a identificação dos autores para fins de responsabilidade perante uma ação judicial, logotipos das empresas eram mesclados no cenário, nascendo aí a primeira interação entre elementos gráficos e cinematográficos:

'Com um galo, uma águia, uma margarida, uma estrela preta ou iniciais dissimuladas nos cenários dos

filmes, as primeiras produtoras tentam controlar uma indústria ainda sem leis. (Toulet, 1999:77)'

Antes de se estabelecer a noção de astros e estrelas de cinema como geradores de bilheteria ou da sindicalização dos empregados da indústria avançar e exigir o registro dos envolvidos nos créditos em tela, a primeira razão para que se ligassem comunicação gráfica e cinema foi a proteção de cada investidor e de seus investimentos. Daí a origem também da designação de créditos. A quem pertence o filme, afinal? A quem daremos o crédito?

Em suas primeiras aparições, os elementos gráficos representados por cartelas com tipografia ou pequenas imagens estáticas eram incorporados com algo que ainda lhes é muito caro e específico. Diagramar, fazer o layout, enfim, criar a aparência visual de uma peça de comunicação gráfica consistia -como consiste hoje ainda, mesmo que com outras ferramentasem pensar em tamanhos, proporções, posição, leitura e visibilidade dos elementos, pensando-os estáticos e constantes no tempo. Mesmo com a familiaridade de ferramentas que possibilitam a passagem de logomarcas do estático ao animado, criar comunicação gráfica tem sólidas raízes e preocupações com o domínio do espaço em primeiro lugar. Dominar o tempo e transformar a mensagem gráfica ao longo dele é a contribuição oriunda do cinema.

Seja pelo tédio do público que desejava novidades, seja pelas tentativas de contar histórias mais sofisticadas, seja meramente pela experimentação com possibilidades técnicas, a articulação da linguagem cinematográfica em poucos anos transcendeu o mero registro e sofisticou-se em suas competências específicas (montagem, som, efeitos visuais, etc.) além de hibridizar-se progressivamente com elementos gráficos. Um fruto desta hibridização é a animação a partir de personagens desenhados. Não por acaso, os primeiros exemplos de filmes animados são realizados por cartunistas e, no caso de Little Nemo in Slumberland (1911) de Winsor McKay, são mescladas cenas de McKay apostando com seus amigos que será capaz de produzir 4000 desenhos em um mês com a posterior apresentação de tais desenhos e a criação de sua animação. O que é gráfico se faz cinematográfico e retorna aos cartuns estáticos ao final do curta. Anos mais tarde, tais sementes da animação fomentariam créditos como os da série A Pantera Cor-de-Rosa e James Bond.

Revela-se então uma característica peculiar no que diz respeito à linguagem 
cinematográfica e à comunicação gráfica: é muito mais rápido e confortável ler seus produtos do que gerá-los. Tal assimetria é determinada pela natureza das imagens (e sons) que constituem os textos de filmes, créditos e produtos gráficos. São "imagens técnicas" (Flusser, 1998:13),

produzidas com o auxílio de máquinas, cujo objetivo final é a comunicação entre os seres humanos. O suporte de natureza técnica não é um fim em si (ao contrário do que fazia salivar aos futuristas como Marinetti), mas sim mero veículo para os significantes que colocarão em ação o processo de leitura e significação.

\section{Créditos e taxonomia}

Uma seqüência de créditos não existe sozinha, isolada do filme. Ela colabora com a mensagem mais ampla do filme, mas, ao mesmo tempo, não está restrita pelas escolhas de estilo visual da obra. Um caminho de bom senso é recomendado por Saul Bass:

'[...] parecia para mim que o título deveria ser aproximado de maneira cautelosa, com algum senso de responsabilidade em relação ao filme em si. Minha visão do que ele deveria ser, obviamente, emergia da intenção do filme. (Crook, 1986:12)'

Umberto Eco fala da intenção da obra, a intentio opera, que ofereceria um conjunto máximo de possibilidades de desdobramento e extensão da interpretação. Quem percorre a obra é um leitor empírico criando a partir da leitura uma série de passeios inferenciais, especulações a respeito do rumo da obra nos trechos ainda não lidos:

'Toda vez que o leitor chega a reconhecer no universo da fábula (mesmo que seja ainda parentizado quanto a decisões extensionais) a atuação de uma ação que pode produzir uma mudança no estado do mundo narrado, introduzindo assim novos cursos de eventos, ele é induzido a prever qual será a mudança de estado produzida pela ação e qual será o novo curso de acontecimentos. (Eco, 1986:94)'

O comunicador gráfico se situa em um ponto de vista de cumplicidade com a obra e com os demais que a realizam. Distinto, portanto, de um leitor normal. Ele também faz tal passeio inferencial, mas meses antes das platéias do filme e com a missão de ajudar capturar o interesse delas para a obra:

'Alguns cineastas querem que estes primeiros momentos sejam de tirar o fôlego: eles criam títulos que excitam as glândulas de adrenalina e lançam o espectador dentro do ritmo do filme. Alguns cineastas levantam uma questão ou fornecem pistas. Outros diretores preferem que uma seqüência de títulos seja quase invisível, indistinta e silenciosamente tecida no início do filme. (Curran, 2001:129)'

Uma seqüencia de créditos deve ajudar a enunciar a intenção da obra sob pena de ser taxada como uma bela representante de uma retórica visual vazia, apenas decorativa e sem causas a partir do ou conseqüências no andamento do filme. Tal sombra da irrelevância desagradava Saul Bass:

'Era algo perturbador quando, tendo estabelecido o valor de algum tratamento especial para os títulos do filme, eu via um número deles sendo feitos como um tipo de sapateado irrelevante. Mesmo coerência estilística, parecia, não era suficiente. Mais importante, precisava haver uma atitude compartilhada entre o crédito e o filme... (Crook, 1986:12)'

Esta atitude compartilhada que Bass defende pode ser entendida como um espelhamento temático entre o filme e a seqüência. Este espelhamento reinterpreta a obra maior dentro da menor, escolhendo o que mostrar e o que esconder para preservar o interesse do espectador. As considerações de Boris Tomachevski (1970), ainda que pensando na literatura, se encaixam perfeitamente para ajudar nossa compreensão:

'No decorrer do processo artístico, as frases particulares combinam-se entre si segundo seu sentido e realizam uma certa construção na qual se unem através de uma idéia ou tema comum. As significações dos elementos particulares da obra constituem uma unidade que é o tema (aquilo de que se fala).

(Tomachevski, 1970:169)'

Quando Bass exprime suas preocupações com a coerência entre crédito e filme, ele não apenas está preocupado com a própria vaidade profissional, mas também com um hipotético espectador que irá assistir ao filme, e o quanto o crédito colaborará com a obra ou se resumirá a uma bela capa que encaderna um livro ruim. O ponto que une Eco, Bass e Tomachevski é que os três têm consciência de que este leitor implícito no texto não está na sala de cinema ou confortavelmente instalado em seu home theater, senão em suas próprias imaginações, como uma espécie de orientador do processo criativo. A este amigo imaginário Eco chama de LeitorModelo , aquele que "e chamado a colaborar no desenvolvimento da fábula, antecipando-lhe os 


\section{Infodesıgn}

estados sucessivos"(Eco, 1986:95). Tomachevski afirma que " a figura do leitor está sempre presente na consciência do escritor, embora abstrata, exigindo o esforço deste para ser o leitor de sua obra." (Tomachevski, 1970:170) e, mais explicitamente: "Esta preocupação com um leitor abstrato traduz-se na noção de 'interesse'. [...] Mas o interesse pode tomar formas bastante variadas." (Tomachevski, 1970:170).

Os modos para buscar despertar a atenção e, portanto, o interesse, são os mesmos apelos presentes na retórica clássica, logos, pathos e ethos. Os elementos usados na construção retórico-persuasiva devem, como convém à definição aristotélica, serem extraídos e manipulados a partir do que é o objeto à disposição. Tomachevski sugere que "O tema apresenta uma certa unidade. É constituído de pequenos elementos temáticos dispostos numa certa ordem." (Tomachevski, 1970:172) a estes eles elementos ele dá o nome de motivos, enquanto Eco os nomina como topics.

Os motivos são pequenas partículas da obra, um resumo absoluto de alguma caracteristica ou trecho da história. Tomachevski cita exemplos de motivos como sendo "A noite caiu", "o herói morreu" e "uma carta chegou". São exemplos que podem ser vinculados à organização sintagmática da narrativa da obra. Aos motivos que não podem ser retirados da narrativa sem prejuízo da compreensão, e causalidade, o formalista russo chama de motivos associados e aos demais, de motivos livres. Traçando um paralelo com a relação estabelecida entre o processo retórico e o processo de realização audiovisual, os motivos associados cabem aos enunciadores principais da obra e os motivos livres em um filme caberiam ao eixo paradigmático, às equipes técnico-artísticas.

No caso das seqüências de créditos, elas podem incorporar diferentes tipos de motivos, interpretando-os graficamente, tipograficamente e cinematograficamente. Estes motivos podem tanto ser os associados (partes relevantes da trama) quanto livres (demais questões estéticas, gráficas ou contextuais apresentadas no filme). O uso destes motivos como referências alimentando o processo criativo-persuasivo é definido por Tomachevski como "o sistema de procedimentos que justifica a introdução dos motivos particulares e seus conjuntos [que] chama-se 'motivação'”. (Tomachevski, 1970:184)

A preocupação de Saul Bass com a "atitude compartilhada" entre filme e crédito se constitui, portanto, a partir da qualidade do próprio filme em motivar seus espectadores a assisti-lo com prazer, algo que está imerso na subjetividade de cada um e, portanto, não é objeto deste estudo. Mas somente é garantida pela sensibilidade do comunicador gráfico em encontrar uma solução que respeite a intenção da obra e a ela conduza, além de conseguir formar uma imagem das expectativas de seu leitor em potencial que encontre um correspondente com a dos leitores empíricos do filme e ainda, acima disto tudo, ofereça um equilíbrio entre o conhecido e o inesperado.

Os motivos inspirados pelo filme podem ser interpretados visualmente de diversas maneiras, com predominância das soluções gráficas (ilustrações, diagramas, colagens, animação) e cinematográficas (imagens live action semelhantes às demais partes do filme). Frequentemente uma destas influências se torna dominante sobre a outra na elaboração do discurso visual dos créditos, silenciando a outra ou a reduzindo ao mínimo de interferência possível. Isto pode ser expresso em uma tabela, estabelecendo uma taxonomia cruzando o cinematográfico e o gráfico (tabela 1).

Tabela 1 : Predominância do gráfico ou do cinematográfico 


\begin{tabular}{|c|c|c|}
\hline & Gráfico forte & Gráfico fraco \\
\hline $\begin{array}{l}\text { Cinematográfico } \\
\text { Forte }\end{array}$ & $\begin{array}{l}\text { Tipo 1: } \\
\text { Créditos que privilegiam a } \\
\text { animação e a mescla, unindo o } \\
\text { melhor dos dois mundos. } \\
\text { Prenda-me se for capaz } \\
\text { (Steven Spielberg,2002); } \\
\text { Homem com o Braço de Ouro } \\
\text { (Otto Preminger, 1956); } \\
\text { Monstros S.A. (Pete Docter, } \\
\text { 2001); Adeus, Lênin (Wolfgang } \\
\text { Becker, 2002) }\end{array}$ & $\begin{array}{l}\text { Tipo 2: } \\
\text { Créditos onde a parte gráfica } \\
\text { discretamente acompanha a imagem, } \\
\text { mas esta imagem mantém o interesse } \\
\text { do espectador por suas qualidades } \\
\text { estéticas, emocionais ou informativas. } \\
\text { Reviravolta (Oliver Stone, 1999); } \\
\text { Cassino (Martin Scorsese, 1995), } \\
\text { Sunset Boulevard (Billy Wilder, 1955); } \\
\text { As Horas (Stephen Daldry, 2002) }\end{array}$ \\
\hline $\begin{array}{l}\text { Cinematográfico } \\
\text { Fraco }\end{array}$ & $\begin{array}{l}\text { Tipo 3: } \\
\text { Créditos que privilegiam } \\
\text { tipografia e demais recursos } \\
\text { gráficos a imagens captadas } \\
\text { por câmera: As Virgens } \\
\text { Suicidas (Sofia Coppola, 2000), } \\
\text { Mulheres à Beira de um Ataque } \\
\text { de Nervos (Pedro Almodóvar, } \\
\text { 1988), }\end{array}$ & $\begin{array}{l}\text { Tipo 4: } \\
\text { Créditos que dependem da música } \\
\text { para serem interessantes. Exemplos: } \\
\text { filmes de Woody Allen, Pulp Fiction } \\
\text { (Quentin Tarantino, } 1994 \text { ) ou Kill Bill } \\
\text { vol.1 ( } 2003 \text {, também de Tarantino) Ou } \\
\text { se tornam monótonos e protocolares }\end{array}$ \\
\hline
\end{tabular}

É importante relativizar os conceitos de forte e fraco. Forte não significa bom necessariamente nem fraco, ruim. Retomando o conceito de motivos associados e livres de Tomachevski, forte poderia ser definido como aquele que incorpora alusões visuais a mais motivos associados a partir do tema da obra e fraco aquele que incorpora referências a motivos livres, a uma quantidade menor de motivos associados ou ainda adota uma representação arbitária em relação ao tema da obra.

O quadrante onde o cinematográfico é mais forte que o gráfico, identificado como tipo 2 , representa a grande maioria dos créditos de filmes. O peso principal do contar a história cabe às imagens de câmera, capazes de realizar os apelos retóricos de logos, pathos e ethos ou uma combinação deles. As cenas para o crédito podem ser rodadas durante a fotografia principal do filme (Rodrigues, 2002), recortando seus planos do mesmo tecido fílmico que irá construir toda a obra. Aos textos gráficos cabe o papel de acompanhar a ação captada pela câmera, sendo facilmente esquecidos.

No quadrante onde o gráfico supera o cinematográfico, citado como tipo 3 , se situam boa parte dos créditos realizados até 1940 e estão presentes em desenhos animados até hoje. São créditos baseados em cartões, normalmente contendo texto gráfico, que tomam toda a tela, levemente animados ou não. Ainda que o registro do material gráfico por uma câmera de cinema o transforme em algo cinematográfico, há uma profunda diferença entre a natureza das duas imagens. Apresentando o exemplo da pintura, John Berger comenta:

'Quando uma pintura é reproduzida por uma câmera cinematográfica, ela invariavelmente se torna matéria para o roteiro do diretor. Isso acontece porque um filme se desenrola no tempo e uma pintura não. Num filme, o modo pelo qual uma imagem segue a outra, sua seqüência, constrói um argumento que se torna irreversível. Numa pintura, todos os elementos estão ali para serem vistos simultaneamente. O espectador pode necessitar de tempo para examinar cada elemento da pintura, mas cada vez em que chega a uma conclusão a simultaneidade da pintura encontra-se toda ali, para reverter ou qualificar sua conclusão. (Berger , 1999:28)'

O quadrante onde ambas as infl uências são fracas, apontado como tipo 4, é sugerido para os créditos protocolares, meramente burocráticos, ausentes ou aqueles onde nem o gráfico ou o cinematográfico são os elementos que conduzem os apelos retóricos visuais. O que poderia ser, então? O papel cabe então à música usada nos créditos, como em Kill Bill Vol.1 (Quentin Tarantino, 2003). No filme, o grande motivo que move a trama é o quase assassinato da noiva (Uma Thurman) e sua sede de vingança. A música dos créditos é Bang, Bang, He Shot Me Down interpretada por Nancy Sinatra, uma maneira irônica de introduzir o que vem adiante. Ainda que subaproveitando todos os demais recursos.

Quando tanto o gráfico quanto o cinematográfico estão aproveitados ao máximo (tipo 1) temos créditos baseados em animação com personagens (a síntese máxima de ambos) ou em mesclas entre grafismos e cinema. Este quadrante, ainda que não seja nosso objeto de estudo, é mais comum em chamadas e vinhetas de séries de televisão, especialmente de emissoras de TV por assinatura. Aparentemente - embora não investiguemos isto neste trabalho - há características na imagem de TV que favorecem mais dinamismo visual (como a maior quantidade 


\section{Infodesıgn}

de quadros por segundo e sua atualização), a necessidade de competir com dezenas de outros canais ameaçados sempre pelo controle remoto (aumentando os apelos de persuasão visual) e 0 menor custo de produção, o que liberta os comunicadores gráficos para agirem com mais ousadia.

É possível, ainda, haver um crédito de abertura sem contar com nenhum motivo sugerido pela obra reinterpretado gráfica ou cinematograficamente. Apenas neste caso os créditos serão radicalmente arbitrários em relação ao filme e, portanto, percebidos como mero acessório sem maior relevância. Tal opção está fora da tabela acima por ser algo praticamente ausente no cinema de longa-metragem. Ela sobrevive, ainda que não seja nosso objeto de estudo, na colocação do claquete antes do arquivamento ou distribuição de um filme publicitário para emissoras e agências. Um claquete, neste sentido, é a minuta dos nomes de equipe, título, empresa produtora e data do filme. Apresentado de maneira tipograficamente sóbria, recebe em geral adereços gráficos identificando a empresa produtora. Mas é idêntico na forma para filmes distintos e campanhas de diferentes clientes. O claquete, observe-se, não vai ao ar.

A incorporação de motivos está sempre vinculada ao contexto cultural em que o filme (e seus créditos) são realizados. Créditos vistos hoje como bastante enxutos graficamente, como os de Psicose (Alfred Hitchcock, 1960) foram tidos radicais e inovadores ao buscar expressar a divisão da personalidade de Norman Bates (o assassino) com conjuntos de linhas animadas que se tramavam e separavam. Dentro do contexto modernista da comunicação visual, a síntese reducionista representou uma vanguarda, conforme Saul Bass afirma que "historicamente, identificação era específica, literal, ilustrativa. [...] Então vieram os trabalhos visuais altamente reducionistas, abstratos, formais. Era inusitado e eficiente." (Heller, 1999:75).

A partir das últimas décadas do século XX o desgaste da representação reducionista fomentou um enriquecimento gráfico dos créditos (e de outras formas de comunicação gráfica). Bass afirma que "marcas geralmente são metáforas de alguma espécie" (Heller, 1999:71) e ele mesmo transformou suas metáforas visuais ao incorporar, no crédito de A Era da Inocência (Martin Scorsese, 1991) o desabrochar de flores em câmera acelerada sobre textos de poesias expressando o amadurecimento da personagem de Winona Ryder. Ambos os créditos foram criados pelo mesmo comunicador gráfico, são motivados pelas obras que os contém e pelo destino de seus protagonistas, mas as imagens que apresentam são radicalmente diferentes.

\section{Conclusões}

A separação dos créditos em uma taxonomia de quatro grandes categorias é ambiciosa e corre o risco de oferecer tanto respostas quanto fendas onde as seqüências que não se enquadrassem cairiam.

Tais quadrantes vêm sendo testados e revisados desde 2005, ano da conclusão da dissertação de mestrado do autor (orientado pelo Prof. Dr. Flávio Vinícius Cauduro). As revisões envolvem a discussão em congressos e a apresentação e debate com turmas de alunos de publicidade da FAMECOS-PUCRS na disciplina de Design em Movimento, disciplina lançada a partir da defesa da dissertação. Em uma observação sustentada, os quadrantes têm sido bem sucedidos como ferramenta teórica para analisar créditos já existentes e planejar projetos futuros.

Uma possibilidade não explorada neste texto, por exemplo, é a de créditos que incorporam diferentes combinações de predominâncias. Por exemplo, filmes como Corra Lola Corra (Tom Tykwer, 1998) incorporam praticamente os 4 quadrantes em diferentes momentos do crédito. Isto acontece com razoável freqüência e não invalida os quadrantes. Abre, no entanto, possibilidades de prosseguir a pesquisa e a discussão de hibridizações entre os elementos gráficos e cinematográficos.

\section{Referências}

BARNOUW, Erik. (1993). Documentary: A History of the Non-Fiction Film. Nova lorque : Oxford University Press.

COELHO NETTO, J. T. (1995). Moderno Pós-Moderno (3a edição). São Paulo : lluminuras.

CURRAN, Steven. (2001). Motion Graphics: Graphic Design for Broadcast and Film. Gloucester: Rockport Publishers.

BASS, Saul in. CROOK, Geoffrey. (1986). Television Graphics: From Caption Card to Computer. Oxford: Built By Robots Press.

BERGER, John. (1999). MODOS DE VER. Artemídia ROCCO, Rio de Janeiro.

ECO, Umberto. (1986). Lector in Fabula. São Paulo: Perspectiva. 
FISKE, J. (et al). (1983). Key Concepts in Communication. London : Methuen.

FLUSSER, Vilém. (1998). Ensaio sobre a fotografia; para uma filosofia da técnica. Lisboa: Relógio D'Água.

FREITAS, Cristiane Gutfreind. (2006). O filme e a representação do real. Disponível online na revista "E-Compós", edição n06, agosto de 2006. Consultado na data 02/01/2007, no endereço eletrônico

http://www.compos.org.br/e-compos/adm/documentos/ecompos06_agosto2006 _cristianefreitas.pdf

HELLER, Steve. (1999). Design Literacy (Continued): Understanding Graphic Design Allworth Press.

KATZ, Eprahim. (1998). The Film Encyclopedia (3rd Ed). Perennial.

MANNONI, Laurent. (2003). A Grande Arte da Luz e da Sombra. São Paulo: Editora Senac \& Editora UNESP.

RODRIGUES, Chris. (2002). O CINEMA E A PRODUÇÃO. DP\&A, Rio de Janeiro.

TOMACHEVSKI, B. Temática, in EIKHENBAUM, B. et alii. (1970). Teoria da Literatura: formalistas russos. Porto Alegre: Globo.

TOULET, Emmanuelle. O cinema, invenção do século. São Paulo: Objetiva, 1999.

\section{Sobre o Autor}

Roberto Tietzmann, Formado em publicidade e propaganda, especialista em produção cinematográfica e mestre em comunicação social. Professor na PUC-RS. Roberto pesquisa áreas de interface entre a linguagem cinematográfica e o design gráfico. Além da docência, também dirige e edita obras audiovisuais.

rtietz@pucrs.br 